\section{Experiences of People Keeping a Three Good Things Daily}

\author{
Yamashita $\mathbf{M}^{1 *}$ and Ito $\mathbf{M}^{2}$ \\ ${ }^{1}$ Department of Nursing, The Jikei University School of Nursing, Japan \\ ${ }^{2}$ Department of Religious Culture, Aichi Gakuin University, Japan
}

\begin{abstract}
The Three Good Things Daily is considered an approach using positive psychology to enhance human happiness. For this study, we conducted an interview survey of seven people to clarify their experiences of using the Three Good Things Daily. The survey results revealed that participants' negative emotional experiences decreased, information processing process was invigorated, and self-understanding deepened based on positive emotional experiences. Accordingly, their actions were activated, which changed their daily life experiences and promoted positive aspects of interpersonal relationships. The Three Good Things Daily is expected to be of help in increasing people's well-being.
\end{abstract}

\section{Introduction}

In 1998, Martin Seligman, the president of the American Psychological Association at the time, advocated positive psychology, asserting the need to emphasize positive aspects of human beings. Positive psychology aims at achieving long-lasting human happiness not from the traditional perspectives of human pathology and problem treatment but through devoting attention to the strengths and good aspects that people have [1]. The method, which specifically examines the positive aspects of human beings, has been used in various fields, including economics, pedagogy, psychiatry, and brain science, not limited to psychology. Positive psychology proposes intervention based on strength, gratitude exercises, and the Three Good Things Daily as simple approaches to increase the level of human happiness [2]. The representative approaches include the Three Good Things exercise, for which participants write three good things every day. Doing the exercise every day for a week has effects on increasing happiness levels and decreasing depression. Results show that the effects last for six months [3]. The exercise is world famous because the simple method promises a high level of effectiveness. In Japan, some scattered studies have examined whether diaries to praise oneself or

"Corresponding author: Yamashita M, Department of Nursing, The Jikei University School of Nursing, Japan, Tel: (+81) 3-3480-1151; Fax: (+81)3-3488-7452; Email: myamashita@jikei.ac.jp

Citation: Yamashita M, Ito M (2021) Experiences of People Keeping a Three Good Things Daily. J Pract Prof Nurs 5: 027.

Received: June 09, 2021; Accepted: June 22, 2021; Published: June 29, 2021

Copyright: () 2021 Yamashita M, et al. This is an open-access article distributed under the terms of the Creative Commons Attribution License, which permits unrestricted use, distribution, and reproduction in any medium, provided the original author and source are credited. record positive experiences influence subjective feelings of happiness and positive emotions [4-6]. Overall, the studies found effects on positive emotions. However, they are all investigations in quantitative research and have elucidated no specific effects related to thoughts, emotions, or life. Clarifying individual qualitative experiences that cannot be measured by numbers is important. This study clarifies what experiences participants have through the use of the Three Good Things Daily.

\section{Defenition of Terms}

The Three Good Things Daily is an exercise done at the end of each day whereby one chooses and writes down three good things (positive experiences) that happened during the day along with the reasons for them.

\section{Methods}

\section{Study design}

This study was designed to be qualitative and descriptive, using an interview survey.

\section{Participants}

We studied seven people who participated in online yoga training delivered via Zoom and who consented to participation in this study.

\section{Data collection period}

Data were collected during November 2020 through December 2020 .

\section{Data collection methods}

A yoga training program in which a co-investigator in this study serves as an instructor implements a one-week exercise of the Three Good Things Daily. After the yoga training, the co-investigator asked training participants to participate in the study via email. The principal investigator gave an explanation based on the informed consent document only to those who expressed their intention of participation via email. After a two-week consideration period, we asked the principal investigator to make email contact with people only if they consented. The principal investigator arranged the interview schedule with participants who expressed their consent and conducted Zoom interviews on their desired date and time. The interviews were conducted on a one-to-one basis in a private room where the privacy of both the principal investigator and the participant were ensured. With the consent of participants, the interviews were recorded using the Zoom Recording function.

\section{Investigation items}

Participants were asked for their age, gender, occupation, highest level of education completed, and family composition. We conducted semi-structured interviews to explore their experiences with the Three Good Things Daily. 


\section{Data analysis methods}

We calculated the descriptive statistics values of participants' basic attributes. The audio data recorded using the Zoom Recording function were converted into text data as a word-for-word record. Researchers conducting the study read the word-for-word record repeatedly, underlined the phrases describing the experiences of the Three Good Things Daily in the description, and extracted phrases that showed the cohesion of meaning. The researchers added their interpretations of what meaning the extracted phrases had. Being careful not to lose the characteristics of the participant's description, we deleted obvious digressions and repetitions. Each extracted phrase was given a code related to the effects of the Three Good Things Daily after being checked against our research questions. Some parts of the participants' descriptions were used as codes. We examined the relations between each code, elucidating patterns and deriving sub-categories. Furthermore, we examined the relations among sub-categories, identifying patterns and generating categories. To ensure the rigour of our results by elucidating whether the authors' interpretations and categorisation were distorted or biased, a discussion was held with three researchers who have conducted qualitative research.

\section{Ethical Consideration}

This study was implemented after obtaining approval from the ethics review committee at the affiliated university (approved number 10322). All participants provided informed consent after receiving the following explanations orally and in writing: participation is on a voluntary basis; there is no disadvantage for not participating in the study or for revoking the consent given; careful consideration is given so that individuals are not identified; and data are managed strictly.

\section{Results}

\section{Attributes of participants}

The seven participants, all women, were of 33.8 years mean age (SD 10.4). The participants comprised four working people, including office workers and self-employed persons, one student, and two people without occupation. Of the participants, two had graduated from high school (one of whom was enrolled in a university), three had graduated from university, and two had graduated from junior college and vocational school as their highest level of education completed. All lived with their respective families.

\section{Experiences of the three good things Daily}

Seven elements were extracted as changes and effects induced by implementation of the Three Good Things Daily: \{Experiences of positive emotions $\}$, \{Experiences of decreased negative emotions\}, \{Invigoration of the information processing process\}, \{Deepening of self-understanding\}, \{Activation of actions\}, \{Changes in daily life experiences\}, and \{Promotion of the positive aspects of interpersonal relationships $\}$. Hereinafter, categories are marked with \{\} brackets, sub-categories with square [ ] brackets, and codes with angular $<>$ brackets. \{Experiences of positive emotions\} Participants experienced various positive emotions, including [Feel calm in mind], [Create room in mind], [Increase a sense of happiness], [Develop a sense of gratitude], [Increase a sense of fulfilment], [Feel relieved], and [Become positive].

\{Experiences of decreased negative emotions $\}$ Participants experienced that [Negative emotions decrease], including $<$ Not take negative experiences as seriously as before $>$ and $<$ Negative emotions decrease naturally $>$. In addition, their experiences of negative emotions decreased by the fact that [Negative emotions do not last], including $<$ Was able to take a feeling of loneliness in stride $>$ and $<$ Leave no melancholia for tomorrow $>$. \{Invigoration of the information processing process $\}$ Participants had experiences of [Expanded attention] such as $<$ My horizons were broadened $>$. They also had experiences of [Filter out unimportant information], including $<$ Be able to see the next even if failed $>$ and $<$ Not think back to bad things $>$. Participants had the experience of invigorating the information processing process as follows: [Pay attention to positive information], including $<$ My brain tries to find good things on its own $>,<$ Be able to notice good things that might have flown away $>$ and $<$ Have more time to think about things that I have worked hard at and am glad to have done $>$; [Process information positively] such as $<$ Be able to think positively during negative experiences $>$; [Reduce excessive expectations for self] such as $<$ Not set a goal of perfection $>$; [Increase a sense of expectation] such as $<$ Want to use the given time to link to something $>$; and [Accept phenomena] including $<$ Think that what has happened cannot be helped $>,<$ Accept the reality calmly $>$ and $<$ Acceptance of stressors $>$.

\{Deepening of self-understanding\} [Confrontation with self] such as $<$ Be able to become sensitive to my mind $>$ became possible. Accordingly, [Awareness of own thoughts] such as $<$ Was able to become aware of my thought process $>$ and [Awareness of own emotions] such as $<$ Awareness of myself thinking about negative things $>$ occurred. Participants had the experience of deepening self-understanding. \{Activation of actions\} Participants found the following activation of actions: [Improve action planning] such as $<$ Be able to act preemptively>, [Increase the speed of action], [Raise the efficacy of action], [Expand the sphere of action] and [Reduce the burden of action]. \{Changes in daily life experiences\} Participants experienced that their lives had changed positively as follows: [Enjoy daily life] including $<$ No longer let the days pass me by $>$ and $<$ Be able to take a pause on days passing so quickly $>$; [Have positive experiences] such as $<$ Successful experiences increase $>$; and [Have a better quality of sleep] including $<$ Be able to sleep comfortably $>$ and $<$ Be able to wake up feeling refreshed in the morning $>$. \{Promotion of the positive aspects of interpersonal relationships $\}$ The category comprises the following sub-categories and codes: [A sense of gratitude toward others] such as $<$ Came to have a sense of gratitude toward my family>; [A sense of compassion for others] including <Want to make people happy $>$ and $<$ Want to please people $>$; [Compassionate actions for others] including $<$ Became gentle to the other person $>$ and $<$ Have a conversation considering the other person $>$; [Positive changes occur in the relationship] such as $<$ Was able to develop a good relationship $>$; [Increase of extroversion], including $<\mathrm{Be}$ able to move into action voluntarily $>$ and $<$ Make plans for friends $>$; [Changes in the mode of relating to others], including $<$ Be able to appreciate myself and people around me $>$ and $<$ Not expect others $>$; and [Care about connections with others] such as $<$ Once again feel important to relate to others>. The positive aspects of interpersonal relationships were promoted by caring feelings and actions (Figure 1).

\section{Discussion}

We conducted interviews with seven participants about their experience of keeping the Three Good Things Daily. The interview results revealed effects on personal emotions, such as increased positive emotions and decreased levels of depression, which have been evident as effects of the implementation of the Three Good Things Daily. Additionally, it was revealed that the implementation had effects on 


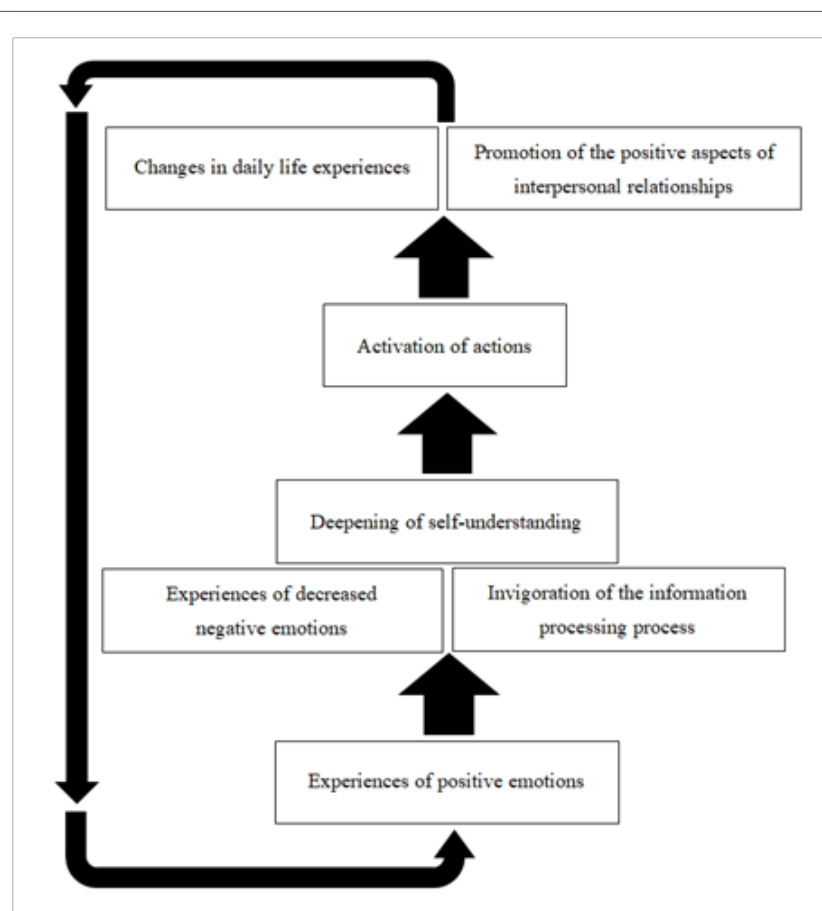

Figure 1: Construction of the effects for the Three Good Things Daily.

widely various matters, from cognition and action to interpersonal relationships and daily life. Negativity bias exists as a phenomenon associated with our information processing. It is a function to keep negative information in memory for a long time by paying more attention to and valuing it than positive information. [7] The human brain has developed to be sensitive to matters that put us at risk and to remember those matters for long periods to avoid danger. Negativity bias is a function that is necessary for self-protection. However, retaining memories of negative information selectively for a long time increases the ratio of negative emotions. Some researchers report that negative emotions activate the autonomic nervous system and maintain that such a state has adverse effects on mental and physical health [8]. This study showed that participants' positive emotional experiences significantly increased by keeping a Three Good Things Daily. The exercise, for which participants write down three good things from the events that happened during the day, enabled them to reduce negativity bias by devoting attention to positive information consciously and to re-experience positive emotions that occur along with good events. It has been pointed out that negative emotions narrow attention and enhance local cognition whereas positive emotions broaden the scope of attention and improve overall cognition and processing [9]. Moreover, in this study, participants' information processing process was invigorated because of the increased experiences of positive emotions. For example, participants expanded attention, filtered out unimportant information, and processed information positively. Our findings support those of the earlier study. In the area of social cognition research, some researchers have pointed out the mood-congruent judgment effect [10]. It is an effect by which positive and favourable evaluations are more likely to be given when people are in positive moods. Negative and unfavourable evaluations are given in negative moods. In this study, participants processed information not only quickly and efficiently but also processed positively. It is inferred that the implementation of the Three Good Things Daily caused positive, favourable evaluations based on the experience of positive emotions.
The Three Good Things Daily is not an ordinary Daily in which people can write whatever they like. Rather, participants must write down three good events and why they occurred. To write the Daily, people must confront and interpret the situation and the self at that time. Participants experienced having an awareness of their own thoughts and emotions by writing the Three Good Things Daily, which deepened their self-understanding. [11] points out that, whereas negative emotions limit people's repertoires of thoughts and actions, positive emotions have the effect of broadening them. In addition, positive emotions improve efficiency $[12,13]$ generate an expansion of choices, and broaden selectable behavioural options [14] Researchers point out positive emotions as a phenomenon of the expansion of thought-action repertoires. This study revealed the activation of actions by positive emotional experiences. Participants improved planning, increased the speed and efficiency of actions, and expanded the sphere of action.

Participants' actions were activated based on positive emotions, which brought positive effects on their daily life experiences and interpersonal relationships. Although it might be inferred that activation of actions increased positive experiences themselves, the information processing process that interprets experiences positively might affect daily life experiences and interpersonal relationships. The more positive emotions one experiences, the greater is one's increased sense of trust for others [15]. Accordingly, some researchers point out that the opportunity to develop diverse ties increases, which increases the opportunity to foster mutual dependence [16] positive emotions, can be characterized as effective to improve interpersonal relationships. The implementation of the Three Good Things Daily in this study brought to light that it had effects not only on positive emotions but also on widely various areas, from the information processing process and the activation of actions to daily life and interpersonal relationships. The Three Good Things Daily is a simple exercise that anyone can do before going to bed, simply by writing three good things and why they happened. The act of recalling positive events reduces negativity bias and forms the habit of turning attention to positive events. The experience of positive emotions increases by turning attention to positive events. Participants' negative emotional experiences decreased, information processing process was invigorated, and self-understanding

\begin{tabular}{|c|c|}
\hline Category & Sub-category \\
\hline \multirow{7}{*}{ Experiences of positive emotions } & Feel calm in mind \\
\hline & Create room in mind \\
\hline & Increase a sense of happiness \\
\hline & Develop a sense of gratitude \\
\hline & Increase a sense of fulfilment \\
\hline & Feel relieved \\
\hline & Become positive \\
\hline \multirow{2}{*}{$\begin{array}{l}\text { Experiences of decreased negative } \\
\text { emotions }\end{array}$} & Negative emotions do not last. \\
\hline & Negative emotions decrease. \\
\hline \multirow{7}{*}{$\begin{array}{c}\text { Invigoration of the information processing } \\
\text { process }\end{array}$} & Expand attention \\
\hline & Filter out unimportant information \\
\hline & Devote attention to positive information \\
\hline & Process information positively \\
\hline & Reduce excessive expectations for self \\
\hline & Increase a sense of expectation \\
\hline & Accept phenomena \\
\hline
\end{tabular}




\begin{tabular}{|c|c|}
\hline \multirow{4}{*}{ Deepening of self-understanding } & Awareness of own thoughts \\
\cline { 2 - 2 } & Awareness of own emotions \\
\cline { 2 - 2 } & Confrontation with self \\
\hline \multirow{4}{*}{ Activation of actions } & Improve action planning \\
\cline { 2 - 2 } & Increase the speed of action \\
\cline { 2 - 2 } & Raise the efficacy of action \\
\hline \multirow{4}{*}{ Changes in daily life experiences } & Expand the sphere of action \\
\hline \multirow{4}{*}{ Promotion of the positive aspects of } & Reduce burdens of action \\
\hline interpersonal relationships & Have positive experiences \\
\cline { 2 - 2 } & Enjoy daily life \\
\hline & Have better quality of sleep \\
\hline & Positive changes occur in the relationship. \\
\cline { 2 - 2 } & A sense of gratitude towards others \\
\hline & Increase of extroversion \\
\hline & Changes in the way of relating to others \\
\hline & Care about connections with others \\
\hline
\end{tabular}

Table 1: Effects of the Three Good Things Daily.

deepened based on positive emotional experiences. Accordingly, their actions were activated, which changed their daily life experiences and which promoted the positive aspects of interpersonal relationships. We think that changes in daily life experiences and good interpersonal relationships further increase positive emotions and create a positive cycle (Table 1).

The Three Good Things Daily will be of help in increasing people's well-being. This study, a summary of the experiences of seven participants, was limited to persons with no disease or physical or medical condition. Future studies must be conducted with persons who have various disorders and backgrounds, in addition to persons like those examined in the present study, to examine the presence or absence and differences of effects arising from implementation the Three Good Things Daily.

\section{References}

1. Seligman ME (2012) Flourish: A visionary new understanding of happiness and well-being. Simon and Schuster.

2. Bolier L, Haverman M, Westerhof GJ, Riper H, Smit F, et al. (2013) Positive psychology interventions: A meta-analysis of randomized controlled studies. Bio Med Central Public Health 13: 1-20.
3. Seligman ME, Steen TA, Park N, Peterson C (2005) Positive psychology progress: empirical validation of interventions. Am Psychol 60: 410-421.

4. Oda N (2005) Basic research on Daily therapy, Regarding the relationship between Daily types and personality traits. Japan Society of Personality Psychology 14: 81-82.

5. Oda N, Horige K, Matsuoka K (2009) Effects of writing three types of daily diaries on multiple mood states: an examination of the individual difference variables. Artes liberals 85: 31-47.

6. Miyazaki A, Omori E, Kodama Y (2019) Effects of daily positive journals about academic works and job-hunting on irrational beliefs in university students, Bulletin of the College of Humanities and Social Sciences, Ibaraki University, 5: 101-115.

7. Rozin P, Royzman EB (2001) Negativity bias, negativity dominance, and contagion. Personality and Social Psychology Review 5: 296-320.

8. Booth-Kewley S, Friedman HS (1987) Psychological predictors of heart disease: A quantitative review. Psychological Bulletin 101: 343-362.

9. Fredrickson BL, Branigan C (2005) Positive emotions broaden the scope of attention and thought-action repertoires. Cogn Emot 19: 313-332.

10. Kitamura H, Tanaka T (2008) Mood states and information processing strategies the revision of the SAC model, The Bulletin of Faculty of Sociology, Toyo University 45: 87-98.

11. Fredrickson BL (2001) The role of positive emotions in positive psychology: The broaden-and-build theory of positive emotions. Am Psychol 56: 218-226.

12. Isen AM, Means B (1983) The Influence of Positive Affect on Decision Making Strategy. Social Cognition 2: 18-31.

13. Isen AM, Rosenzweig AS, Young MJ (1991) The influence of positive affect on clinical problem solving. Medical Decision Making 11: 221-227.

14. Kahn BE, Isen AM (1993) The influence of positive affect on variety seeking among safe, enjoyable products. Journal of Consumer Research 20: $257-270$.

15. Dunn JR, Schweitzer ME (2005) Feeling and Believing: The Influence of Emotion on Trust. Journal of Personality and Social Psychology 88: 736748 .

16. Cohn MA, Fredrickson BL (2006) Beyond the moment, beyond the self: Shared ground between selective investment theory and the broaden-andbuild theory of positive emotions. Psychological Inquiry 17: 39-44. 


\section{$\mathrm{H}$ \\ maxno}

Advances In Industrial Biotechnology | ISSN: 2639-5665

Advances In Microbiology Research | ISSN: 2689-694X

Archives Of Surgery And Surgical Education | ISSN: 2689-3126

Archives Of Urology

Archives Of Zoological Studies | ISSN: 2640-7779

Current Trends Medical And Biological Engineering

International Journal Of Case Reports And Therapeutic Studies | ISSN: 2689-310X

Journal Of Addiction \& Addictive Disorders | ISSN: 2578-7276

Journal Of Agronomy \& Agricultural Science | ISSN: 2689-8292

Journal Of AIDS Clinical Research \& STDs | ISSN: 2572-7370

Journal Of Alcoholism Drug Abuse \& Substance Dependence | ISSN: 2572-9594

Journal Of Allergy Disorders \& Therapy | ISSN: 2470-749X

Journal Of Alternative Complementary \& Integrative Medicine | ISSN: 2470-7562

Journal Of Alzheimers \& Neurodegenerative Diseases | ISSN: 2572-9608

Journal Of Anesthesia \& Clinical Care | ISSN: 2378-8879

Journal Of Angiology \& Vascular Surgery | ISSN: 2572-7397

Journal Of Animal Research \& Veterinary Science | ISSN: 2639-3751

Journal Of Aquaculture \& Fisheries | ISSN: 2576-5523

Journal Of Atmospheric \& Earth Sciences | ISSN: 2689-8780

Journal Of Biotech Research \& Biochemistry

Journal Of Brain \& Neuroscience Research

Journal Of Cancer Biology \& Treatment | ISSN: 2470-7546

Journal Of Cardiology Study \& Research | ISSN: 2640-768X

Journal Of Cell Biology \& Cell Metabolism | ISSN: 2381-1943

Journal Of Clinical Dermatology \& Therapy | ISSN: 2378-8771

Journal Of Clinical Immunology \& Immunotherapy | ISSN: 2378-8844

Journal Of Clinical Studies \& Medical Case Reports | ISSN: 2378-8801

Journal Of Community Medicine \& Public Health Care | ISSN: 2381-1978

Journal Of Cytology \& Tissue Biology | ISSN: 2378-9107

Journal Of Dairy Research \& Technology | ISSN: 2688-9315

Journal Of Dentistry Oral Health \& Cosmesis | ISSN: 2473-6783

Journal Of Diabetes \& Metabolic Disorders | ISSN: 2381-201X

Journal Of Emergency Medicine Trauma \& Surgical Care | ISSN: 2378-8798

Journal Of Environmental Science Current Research | ISSN: 2643-5020

Journal Of Food Science \& Nutrition | ISSN: 2470-1076

Journal Of Forensic Legal \& Investigative Sciences | ISSN: 2473-733X

Journal Of Gastroenterology \& Hepatology Research | ISSN: 2574-2566
Journal Of Genetics \& Genomic Sciences | ISSN: 2574-2485

Journal Of Gerontology \& Geriatric Medicine | ISSN: 2381-8662

Journal Of Hematology Blood Transfusion \& Disorders | ISSN: 2572-2999

Journal Of Hospice \& Palliative Medical Care

Journal Of Human Endocrinology | ISSN: 2572-9640

Journal Of Infectious \& Non Infectious Diseases | ISSN: 2381-8654

Journal Of Internal Medicine \& Primary Healthcare | ISSN: 2574-2493

Journal Of Light \& Laser Current Trends

Journal Of Medicine Study \& Research | ISSN: 2639-5657

Journal Of Modern Chemical Sciences

Journal Of Nanotechnology Nanomedicine \& Nanobiotechnology | ISSN: 2381-2044

Journal Of Neonatology \& Clinical Pediatrics | ISSN: 2378-878X

Journal Of Nephrology \& Renal Therapy | ISSN: 2473-7313

Journal Of Non Invasive Vascular Investigation | ISSN: 2572-7400

Journal Of Nuclear Medicine Radiology \& Radiation Therapy | ISSN: 2572-7419

Journal Of Obesity \& Weight Loss | ISSN: 2473-7372

Journal Of Ophthalmology \& Clinical Research | ISSN: 2378-8887

Journal Of Orthopedic Research \& Physiotherapy | ISSN: 2381-2052

Journal Of Otolaryngology Head \& Neck Surgery | ISSN: 2573-010X

Journal Of Pathology Clinical \& Medical Research

Journal Of Pharmacology Pharmaceutics \& Pharmacovigilance | ISSN: 2639-5649

Journal Of Physical Medicine Rehabilitation \& Disabilities | ISSN: 2381-8670

Journal Of Plant Science Current Research | ISSN: 2639-3743

Journal Of Practical \& Professional Nursing | ISSN: 2639-5681

Journal Of Protein Research \& Bioinformatics

Journal Of Psychiatry Depression \& Anxiety | ISSN: 2573-0150

Journal Of Pulmonary Medicine \& Respiratory Research | ISSN: 2573-0177

Journal Of Reproductive Medicine Gynaecology \& Obstetrics | ISSN: 2574-2574

Journal Of Stem Cells Research Development \& Therapy | ISSN: 2381-2060

Journal Of Surgery Current Trends \& Innovations | ISSN: 2578-7284

Journal Of Toxicology Current Research | ISSN: 2639-3735

Journal Of Translational Science And Research

Journal Of Vaccines Research \& Vaccination | ISSN: 2573-0193

Journal Of Virology \& Antivirals

Sports Medicine And Injury Care Journal | ISSN: 2689-8829

Trends In Anatomy \& Physiology | ISSN: 2640-7752

Submit Your Manuscript: https://www.heraldopenaccess.us/submit-manuscript 